\title{
Experiences of primary health care nurses in implementing integrated management of childhood illnesses strategy at selected clinics of Limpopo Province
}

\section{EN Vhuromu, M Cur}

School of Health Sciences, University of Venda

M Davhana-Maselesele, D Phil

Faculty of Agriculture; Science and Technology, North West University: Mafikeng campus

\section{Key words}

Integrated Management of Childhood Illnesses; Primary health care nurse; Primary health care; Supermarket approach.

\section{Correspondence address}

Prof M. Davhana-Maselesele

Executive Dean of Faculty of Agricul-

ture; Science and Technology

North West University

(Mafikeng Campus)

Private Bag X2046

Mmabatho, 2735

Tel: (018) 3892050

Fax: (018) 3892052

E-mail:

mashudu.maselesele@nwu.ac.za

\section{Abstract: Curationis 32 (3): 60-71}

Treatment of the under five years is a national priority as an attempt in curbing deaths and deformities affecting children. Primary health care was implemented in the clinics in order to help in the treatment of illnesses affecting the community, including children. As a result of childhood illnesses; the World Health Organization (WHO) and United Nation Children's Fund (UNICEF) came up with Integrated Management of Childhood illnesses (IMCI) strategy to enhance treatment of such illnesses in developing countries. Primary health care nurses (PHCNS) in Limpopo province were also trained to implement the strategy.

This study is intended to explore and describe the experiences of PHCNS in implementing the IMCI strategy at selected clinics in Vhembe District in the Limpopo Province. A qualitative, explorative, descriptive and contextual design was used. Indepth interviews were conducted with PHCNS who are IMCI trained and have implemented the strategy for a period of not less than two years. Data analysis was done through using Tesch's method of open coding for qualitative analysis.

Findings revealed that $P H C N S$ had difficulty in rendering $I M C I$ services due to lack of resources and poor working conditions. Recommendations address the difficulties experienced by PHCNS when implementing the IMCI strategy. 


\section{Introduction and background}

Primary health care (PHC) was introduced to meet the health-care needs of everyone by the year 2000. The approach was used in order to meet the health challenges at that time. Primary health care nurses (PHCNS) were made available at various clinics to provide care. Despite all these efforts, the challenges of health-care provision to children under five years continued to increase in spite of the services rendered by the trained PHCNS. This burden of childhood illnesses, that is, diarrhoea, acute respiratory infection, malaria, measles and malnutrition (DAMMM) led to the need to challenge the role of the PHCNS. A gap was identified in the training of the PHCNS. It was found out that PHCNS training did not prepare them adequately to deal with DAMMM (WHO, 2004a: 3).

The World Health Organisation (WHO) and the United Nation Children's Fund (UNICEF) worked together to design a strategy to integrate all interventions for the prevention, treatment of childhood illnesses and health promotion of children under five years (WHO, 2004b: 1; Tarus, 2004: 2). The intention of the joint initiative was to reduce mortality and morbidity in childhood. It would also promote better conditions for child health and development during the first five years of life. It was hoped that it would increase vaccination coverage and improve knowledge and home-care practices for children under five. The WHO and UNICEF presented Intergrated Management of Childhood illnesses (IMCI) as a principal strategv to improve child health (WHO, 2004b: 1; Tarus, 2004: 2). $I M C l$, as a new strategy, was then introduced since the PHC course did not cover all the areas for dealing with $D A M M M$ effectively.

According to WHO (2004b:2; 2003:l), the aims of the IMCI were to identify the childhoodillnesses accurately, give appropriate treatment, speed up referral of children to the hospital or any other health service and give attention to immunization, Vitamin A supplementation and exclusive breast feeding. Listening, learning and building confidence skills are taught or developed as part of counselling skills (Kamarag.
Lubanga \& Heggenhougen, 2004: 33).

This strategy was then spread to other developing countries until it reached some of the African countries, such as Uganda in June 1995 Kamaragi, et. al (2004:31) and Tanzania, Ethiopia, Mozambique, Botswana and other African countries in 1996, following the first global pretest in Arusha in 1995 (Red Cross Works, 2003:3; WHO, 2002:1).

It was therefore important for health workers to undergo training on the IMCI course, which included the following: methodology and treatment, home visits, health education and other options (Red Cross, 2003:1).

South Africa, like other developing countries in Africa, adopted the IMCI document. IMCI was launched in South Africa 1998. The Department of Health in South Africa developed guidelines to complement the adopted IMCI document. The document was adapted into the South African context and areas that were given priority attention were HIV and AIDS, tuberculosis, ear infections, child abuse, meningitis, malnutrition and management of a critically ill child (WHO, 2002:1).

IMCI training was launched in South Africa in 1998, but in Limpopo Province the first training was conducted in 1999. In Whembe district the first group of nurses was trained in 2001. At present almost all the clinics have one or more PHCNS who are IMCI trained. During 2009, there were $20 \mathrm{IMCI}$ facilitators and about 200 IMCI-trained nurses in Vhembe district. The nursing schools, colleges and universities have started training IMCI facilitators. This is intended to ensure that IMCI is incorporated into all nursing curricula. IMCI is now compulsory for all heath workers. It is being incorporated into the basic training curriculum so that all health workers will be able to implement it, including doctors (WHO, 2002:1). Although the aim of IMCI training is for all health workers, the priority target group is PHCN as they are the major workforce rendering primary health care at the clinics.

\section{Problem Statement}

Department of Health created a post for an officer who deals with IMCI issues at national, provincial and district level. This appointment indicated the seriousness of South Africa in ensuring effective implementation of IMCI. $P H C N S$ are taken from their clinics at scheduled times and undergo two weeks' training in IMCI.

Shayandima catchment area has about 18 PHCNS who are IMCI trained. The researcher was interested in inquiring about PHCNS' experiences regarding implemention of IMCI, as this was a new strategy. The researcher wanted to find out how the PHCNS were experiencing the implementation of the IMCI strategy, in order to identify areas that needed improvement based on the information gathered from nurses who were involved with it on daily basis. In order to understand the context in which the PHCNS are functioning, the researcher asked the following two questions which guided the study:

- How do you experience the rendering of IMCI services in this clinic where you are currently working?

- What do you think should be done to improve or strengthen the delivery of IMCI services?

\section{Objectives of the study}

The objectives of the study were to:

- $\quad$ explore and describe the experiences of PHCNS when rendering IMCI services.

- develop recommendations that would improve implementation of IMCI services.

\section{Definition of terms}

Primary health-care nurse: $A$ nurse registered with the South African Nursing Council (SANC), who has a certificate in Primary Health Care, diagnosis and treatment.

Integrated Management of Childhood Inesses: $A$ health-care strategy introduced to treat illnesses of children underfive.

IMCI Training: A ten-day training course that is conducted by IMCI facilitators for health-care professionals. In this study the course is for PHCNS only.

Supermarket approach: The approach that is used to treat the client for all the problems in one consultation at a health care institution. This means that a client visit the clinic and receive care 
without giving specific days for special clinics.

\section{Research design and method}

According to Babbie and Mouton (2002:647), research design is a structured framework on how the researcher intends conducting the research process in order to solve the researched problem. A qualitative research design which is explorative, descriptive and contextual was used in order to explore and describe the experiences of PHCNS when rendering IMCI services. The researcher used qualitative design in this study in order to collect detailed information about the experiences of $P H C N S$ when rendering IMCI services. According to Brink (2006:11) explorative study is conducted to explore the dimensions of a phenomenon, the manner in which it is manifested and the other factors which are related. As IMCI strategy is new, the researcher decided to use the explorative design to pursue the experiences of $\mathrm{PHCN}$ in depth and familiarize herself with these experiences. According to Babbie (2004:89), descriptive designs involve observations that are deliberate and careful to ensure accuracy and precision. The study was descriptive as participants themselves were narrating their experiences while the researcher was observing and listening to ensure accurate and precise description of those experiences

According to Terre Blanche and Durrheim (2004:127) researchers want to make sense of feelings, experiences, social situations or phenomenon, as they occur in the real world, therefore data need to be collected in the real setting. Contextual design was used in this research because participants were interviewed within their environmental setting (within their own contexts), that is, at the clinic where they are or were working

The researcher used her judgment to determine the size of the sample since there were not many participants, and not much had been researched about this topic. This allowed participants to articulate their experiences since IMCI was still a new strategy that was being implemented. According to Babbie and Mouton (2002:288), adequate time and current involvement are criteria for selection of participants who have the best answers to the research question. In this research the sample was formed by PHCNS who:

- had undergone a two weeks, IMCI course;

- were rendering IMCI services at Shayandima catchment area, Thulamela Municipality clinics of Vhembe district in Limpopo Province;

- $\quad$ had implemented the IMCI strategy for not less than one year; and

- had given informed voluntary consent to participate in the study.

According to De Vos, Strydom, Fouche and Delport (2002:304) and Holiday (2002:79), the aim of data collection is to provide a contextual experience, revealing an experience as a process. According to Newman (2000:33), it is through skill, practice and creativity that one matches a research question to an appropriate data collection technique.

According to Burns and Grove (2001:594), an in-depth individual interview is used by researchers to obtain more information from participants. In this research an in depth individual interviews were conducted with PHCNS rendering IMCI services at all the clinics. One main question was asked and subsequent questions were asked as responses to the participant's answers.

According to Mayan (2001:33), the researcher leads the discussions by asking an off-the-ground question. Thereafter the questions are directed by the responses that are given by the participant. In this research one question was asked and subsequent questions asked emanated from the participant's answers. The researcher was able to collect narrative and subjective information from participants. The researcher used communication skill to probe the participants to say more in the discussion (De Vos et. al 2002:257289).

During interviews data was collected, audio taped, and transcribed verbatim. Literature was controlled. Co-coding was done. Data were analysed using
Tesch's eight steps as described by (Cresswell, 1996:155).

\section{Measures to ensure trustworthiness}

Truth value is achieved by ensuring credibility (Cresswell 1996:217). The researcher was engaged in prolonged interaction with the participants, collecting data until data saturation had been reached, so they develop trust in the researcher and this made them feel free to talk. Field notes were taken to rationalize the relationship between the researcher and the setting, that is, to ensure structural coherence.

Applicability was achieved by transferability. The researcher collected sufficient detailed descriptions of data in context. According to Rice and Ezzy (2001:38), triangulation involves multiple research methodologies. In this study triangulation was used as different methods of data collection, namely, in depth individual interview and field notes were used.

To ensure consistency, dependability was used (Cresswell, 1996:217). A dense description of the research method was done to ensure dependability. Structural coherence was ensured by means of peer group reviews, presentation and member checking.

The strategy applied to achieve neutrality is conformability (Cresswell 1996:21). This means the research study was not influenced by any bias of the researcher. It is a true reflection of the $P H C N$ 's experiences as objectivity was maintained through coding, recording, editing and triangulation.

\section{Ethical considerations}

The researcher received ethical clearance from the University of Venda's Ethics Committee. Permission was granted to conduct the study by the Limpopo Provincial Research Ethics ' Committee and the Shayandima catchment area supervisors.

According to Henning, van Rensburg and Smith (2002:73) participants need to give informed consent in relation to participating, interviews, privacy, sensitivity and use of information. Participation was voluntary in that partici- 
pants gave their informed consent before participating in this research study. In this research participants were not harmed psychologically as they were informed that no thorny questions would be asked and that if they felt that they didn't want to answer a specific question they were allowed to desist. They were assured that their information would never be used against them.

\section{Discussion of findings}

One theme that emerged during the interviews was: PHCN experience difficulty in rendering IMCI services. This theme is supported by the categories and subcategories as summarized in table 1. A discussion of subcategories is supported by direct quotes from participants as well as a literature control.

\section{PHCNS experience difficulties in rendering $\mathrm{IMCl}$ services}

PHCNS experienced difficulty in rendering IMCI services. They expressed their concern regarding implementation of the IMCI strategy. Although they appreciated the initiative (IMCI strategv) they indicated that they lacked the necessary resources and their working conditions were poor to an extent that it hampered the effectiveness of the implementation of the strategy. The category and subcategories are discussed in detail in the following paragraph.

\section{- $\quad$ Lack of resources}

Resources play a major role in the implementation of IMCI. PHCNS indicated that they experienced difficulties in rendering IMCI services because of lack of these resources. The two subcategories that were identified, namely, lack of human and lack of material resources will be discussed in detail.

\section{$o \quad$ Lack of human resource}

PHCNS confirmed difficulties as far as rendering IMCI services was concerned, due to lack of sufficient staff. The participants expressed lack of human resources as follows:

"It's very difficult when it comes to rendering IMCI services. (Shaking the head continuously) We work as a team of four PHCNS. All of us are IMCI trained; two of us work per shift. Showing this by counting the fingers) We don't have other lower nursing categories".

PHCNS indicated that there were many activities that needed to be undertaken when rendering IMCI services. This was supported by participants who said:

"This was aggravated by the fact that activities done when assessing and treating an ill child in IMCI are many and the same irrespective of the child's major problem. "
According to UNICEF (2000:4-19), assessment of every child in IMCI includes assessment of danger signs, coughing and difficulty in breathing, diarrhoea, fever, ear infection, malnutrition, anaemia, HIV/AIDS, the mother's condition and any other symptoms the child might be experiencing. Although these activities are necessary to manage childhood conditions it is important to have enough staff complement.

"In IMCI counselling is done more frequently and the aim thereof is to change the mother or the child minder's attitude, skills, knowledge and behaviour. This is not achieved at its best because it needs manpower. We cannot achieve this if you still find one PHCN working per shiff because there is nobody to relieve the one who is not in."

According to Karamagi, et al. (2004:31), counselling is a key component of the guidelines for IMCI. It is done to provide accurate information and skills so as to empower the mother or child minder to take decisions that improve the situation for the child and family.

PHCNS said that the situation was made worse by the fact that they were faced with other responsibilities. One of the PHCNS said that:

Table 1

THEME : PHCNS experience difficulties in rendering $\mathrm{IMCl}$ services

\begin{tabular}{|c|c|}
\hline CATEGORY & SUBCATEGORY \\
\hline Lack of resources & $\begin{array}{ll}\text { - } & \text { Lack of Human resources } \\
\text { - } & \text { Lack of Material resources } \\
\text { - } & \text { Shortage of Medication } \\
\text { - } & \text { Absence of Computers at Clinics } \\
\text { - } & \text { Lack of Physical resources }\end{array}$ \\
\hline $\begin{array}{l}\text { Poor working conditions which have a negative impact on } \\
\text { the PHCNS }\end{array}$ & 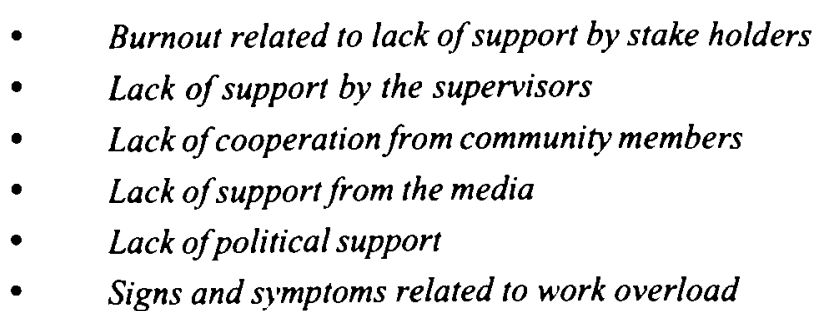 \\
\hline
\end{tabular}


"There is too much activities done at the clinic. My hands are full. I have other responsibilities. I work as an administrator: Isupervise, control and assess staff I provide care for clients with different health problems, such as TB (tuberculosis), mental illnesses, cancer, pregnant mothers, patients with other chronic conditions, you name them. It is a lot really. One cannot cope ... It is so painful I am telling you."

According to Bryce, Victora and Habicht (2004:406-411), one component of IMCI involves a process of assessment of signs and symptoms, classifying the illness on the basis of treatment needs, providing appropriate treatment to and education of the child's care giver. It also includes identifying malnutrition and anaemia and checking vaccination status, providing nutritional care, counselling, and communicating effectively with mothers. All these activities need adequate staff to implement them. This is the situation in which the PHCNS has nobody to whom to delegate the work. In such situations some of the nursing duties are not done, or if done the incorrect procedures are followed. Participants indicated that they were using the supermarket method of rendering patient care including the implementation of IMCI. This is supported by the following statement:

"...You attend to an ill child. followed by one with a wound which needs to be dressed. you have to go to the dressing room. Then a child comes in with HIV and AIDS-related problems that will need assessment, counselling and testing and so on and so on. You never become settled You jump from one activity to another. I work in this fashion from sunrise to sunset)."

The supermarket strategy of rendering health services involves treating patients as they consult, without grouping them to come to the clinic on a particular day or time. The supermarket strategy combines the various special clinics into one visit. Patients are treated as they come into the consultation room for whatever problem they have. There is no longer a flow of work. The PHCN moves from one type of task to another.

Participants indicated that due to the supermarket method, one type of health education which is to be given to almost all the patients is to be repeated many times to individual mothers as they consult. Participants expressed the giving of health education in the supermarket method as follows:

"When health education is given you also have to repeat yourself many times because patients who need the same type of health education will be coming one by one at different times. At the end of the day you still have to repeat. This becomes boring and tiresome".

This can be time-wasting and tiresome and the education is not given logically. Mothers end up not getting the same information. This is supported by a study done by Nemathaga (2005:64), that when using the supermarket approach health education is not given the attention it deserves. She agues that health education is either not given, or if given, it is done haphazardly because the PHCN does not have enough time for this. PHCN indicated that shortage of human resources is further complicated by the many activities that have been introduced without increasing the stafflng.

IMCI, like any other strategy, increased the workload. All these activities increased the workload of the already overworked PHCN.

"With us the staffis still the same from the time when PHC was implemented, the free health services, supermarket strategy and now IMCI. There is no change of staff We are now over worked. This has affected other activities such as implementation of IMCI, home visits and participation in the community project, of which we are expected to have one each year"

"I cannot make it. I see more than 40 babies per day. This excludes the other parients. "

This is supported by McCoy, Besser, Visser and Doherty's (2002:36) study, which confirms that when prevention of mother to child transmission (PMTCT) was introduced the workload was added but this was not compensated for by additional staff WHO (2003-2007:14) supports this as it indicates that the introduction of PMTCT and antiretroviral therapy (ARVT) in $B o t s w a n a$, resulted in increased workload for the already overstretched workforce resulting in overworking of staff. This implied that the PHCN rendering IMCI services at Shayandima catchment area who are also implementing the very PMTCT, ARVT and IMCI are not exceptional.

According to the study by Wirzba and Juncker (1995: 33), time spent on IMCI assessment and treatment of a child is approximately 40 minutes excluding giving of health education and counselling. This gives us an estimation of about seven children that can be treated per day per $P H C N$ when using the IMCI strategy. This number excludes other patients. None of the clinic staff structures accommodate this number of children. There is not enough staff to implement IMCI fully and this makes rendering of IMCI services difficult.

\section{$o \quad$ Lack of material resources} Implementation of IMCI needs material resources to ease and hasten the assessment in order to make a proper diagnoses and treatment of the child effectively. So without the necessary resources it is difficult for the PHCNS to implement the IMCI strategy.

"It is long that we have been working without a scale. We have condemned it but we are still waiting for delivery of the new one. This makes the implementation of IMCI difficult, especially when it comes to the calculation of dosage of medication, fluid replacement measurement and nutritional assessment."

When rendering IMCI services the scale is used to estimate the amount of oral rehydration fluid to be given per child's weight under the observation of the PHCN at the rehydration corner WHO and UNICEF (2002a:20-21). A child weighing $7 \mathrm{~kg}$ is to be given 500 mg of cotriazone WHO and UNICEF (2002b:61).

The assessment of a child is obviously not accurate as they are going to use subjective data. This was supported by the participant who said:

\footnotetext{
"The broken thermometers are not quickly replaced. This makes it diffi-
} 
cult for me to use accurate information for making the right diagnosis and treatment in IMCI At times l just refer the child to the hospital because the child's body is hot. What can I do? (Facing at me like I would come up with an answer MM....!) There is nothing that I can do (With low voice)."

According to WHO (2002:23) a child with a temperature of 38 degrees Celsius should be given Paracetamol every 6 hours. Chaudhary, Mohanty and Sharma (2005:739) found that health workers working without thermometers or minute sound timers compromises the assessment of children and may lead to wrong assessment, diagnosis and treatment.

Participants supported that they were failing to test children for malaria or HIV due to shortage of malaria and HIV testing equipment when they said:

"We at times work without malaria testing equipment or HIV rest kits or buffers. In such situations I either refer the patient to the hospital, community organization or give them a return date. We lose some of them by doing this. Some of them go for good This becomes a fruitless exercise as the process will come to a standstill because of shortage of the necessary material To counsel a client takes a lot of time. This experience is tiresome and wastes a lot of time. After counselling I will still find other patients waiting for me."

According to IMCI every child coming from a declared malaria area is supposed to be tested for malaria (WHO and UNICEF, 2002b:56). It is unfortunate because Vhembe District is declared a malaria area, but PHCNS do not afford to always do the test because of not having the necessary equipment.

"When mothers leave the clinic without undergoing a particular test, she goes for good. This is because the client's readiness for the test will be disturbed as they are told to come back for the test or be referred to the hospital or community organization for that. Such incidents waste time because more time is spent counselling those mothers who have children with $H I V$ and $A I D S$ - related symptoms and in the end we don't achieve the goal. In IMCI every child presenting with $H I V$ and $A I D S$-related symptoms, the mother has to be counselled so that she can voluntarily agree to testing of both."

WHO and UNICEF (2002a:19) stress that a child with continuous loss of weight should have the mother counselled so that she can voluntarily agree to HIV testing of both the mother and her child. According to Igumbor, Bradshow and Laubscher (2003:23) HIV/AIDS accounts for $38 \%$ of total burden of the causes of premature deaths.

\section{$o \quad$ Shortage of Medication}

Participants verbalized the shortage of medication.

"Shortage of medication sometimes takes too long to an extent that patients even become aware that it's long that there is no medication. This hampers the implementation of IMCI, though we at times refer the mothers unnecessarily to the hospital for collection of medication."

According to Bryce et. al (2004:406), the second component of IMCI is to improve the health-system support for child health service delivery. This includes availability of drugs to be prescribed for children when it is necessary.

The situation is worsened by the use of the supermarket system in that a vaccine could not be used up within the prescribed time. A participant said:

"The vaccines expire 5 hours after being opened. So if supermarket strategy is used one vaccine cannot be shared among children like it would be on a special baby clinic day where one vaccine may be used for many babies at the same time as there would be many who came to clinic for vaccination."

According to the WHO (2003-2007:15), shortages of pharmaceuticals and vaccines have been reported especially at the peripheral health facilities of Botswana. It will be difficult for the PHCNS to render IMCI services of high quality and effectively when there is no medication available.

\section{o Absence of Computers at Clinics}

The researcher observed that the clin- ics had no computers. In support of this the PHCN said that:

"There are no computers in the clinics. Computers may be very useful for record keeping, information and production of different forms that are useful at the clinic including the very assessment forms that are used every day for every child"

According to Critchton and Botman (2002:22-27) the University of the Free State developed a World Wide Web (WebCT) course tool which provides the software tools necessary to create. deliver and manage an IMCI course over the WebCT. So the PHCN would be able to access this information if there were computers with internet facilities at the clinics. This would also help to update the PHCN with recent developments and knowledge in IMCI.

o Lack of Physical resources

Buildings in the clinics are needed for the rendering of IMCI services. PHCNS said that clinics were very small and there were not enough rooms to accommodate the services rendered at the clinic. A participant said:

"Clinics lack separate rooms for counselling of patients. This situation makes it difficult to assess or counsel a patient in privacy."

Children with HIV and AIDS-related symptoms have to be counselled for voluntary testing (VCT). Such patients need privacy, time, counselling skills, starting with treatment and information for them to make a decision Kamaragi et. al (2004:431-439). According to WHO (2002: 52-54) lack of a separate room may inhibit some mothers from asking questions about their own health. Privacy is the key issue in counselling and therefore a separate room is recommended.

Participants in some clinics indicated that there was no suitable space for preparation of a dehydration corner. In support of this, participants said:

"There is no open space as the rooms are very' small. This fails us to implement the rehydration plan for a dehydrated baby according to the IMCI standards."

Another participant said:

"There are two consultation rooms with one small waiting room, one 
dressing room and one labour ward. In the mornings when clients are still many, some of the patients wait on benches outside on the veranda. You can see for yourself where we have prepared the rehydration corner, it is not even visible to you."

According to the WHO and UNICEF (2002a:20), a standard rehydration corner is supposed to be in a corner which the staff members frequently pass, near to a water source and well ventilated. The corner should have informative posters displayed. According to $\mathrm{WHO}$ and UNICEF (2002a:67), the instructions in the rehydration corner should be in words and pictures. This will help with the education of the mother while she sits there for treatment of the baby.

\section{- $\quad$ Poor working conditions which have a negative impact on the PHCNS}

Participants expressed that poor working conditions led them to suffer from burnout as a result of the increased workload. The following sub-categories are discussed in detail. Burnout relates to lack of support by stakeholders, as well as signs and symptoms related to increased workload. Each subcategory will be described in detail.

\section{$o \quad$ Burnout related to lack of sup-} port by stakeholders

PHCNS said that they were dissatisfied with the lack of support from different stakeholders such as supervisors, community members, media and politicians. Lack of support by stakeholders resulted in their burnout. According to Greenglass and Burke (2002:89-114), job burnout is one of the most serious occupational health hazards resulting in job dissatisfaction. Adali and Priami (2002:20) consider burnout as the type of professional stress resulting from social interaction between the person who provides help and the person who receive that help.

\section{o Lack of support by the super- visors}

PHCNS indicated that there was poor supervision or follow up as supervisors rarely visited the clinics.

"There is no ssupervision in the true sense. Not to mention support it is worse. We just work day in and day out. Supervisors don 't just come at the clinic."

According to Lehmann and Saunders (2002:133) lack of supervision and support lowers productivity, staff morale and quality of care. It also contributes to the brain drain. This is also supported by Adali and Priami (2002:20) who also identify that lack of support by the supervisor causes burnout. Burnout is a serious problem, particularly with nurses.

o Lack of cooperation from community members

The community members were uncooperative in different ways. Participants indicated that the community had a negative attitude towards assessment and they did not support them during assessment of a child. They indicated that:

"Some mothers are not cooperative during assessment. They grumble to say that they are asked useless questions which are not related to their main problem. At times you can even see that the mothers are just answering to get rid of you."

Participants experienced that mothers were bored by too many questions asked by the PHCNS during assessment. A participant said:

\begin{abstract}
"Why so many questions? Did you observe something abnormal on my child? Hee! Tell me. If the answer is NO, then they will ask, Why then? because I told you my child's problems. It's just flu. only flu. Give me treatment for God's sake! Mothers grumble that their time is wasted"
\end{abstract}

Although there were some of the mothers who appreciated that the nurse was able to identify a health problem about which the mother had been unaware. some mothers had a negative attitude towards the assessment process. This was worsened by the fact that they found the questions too many and irrelevant to their main complaint. They became reluctant to give answers. At times they gave wrong answers thinking that they would shorten the duration of the assessment. This lengthened the duration of the already long assessment period. The IMCI assessment is very different from the old one where the nurse was able to make quick diagnoses from the collection of the information from the mother's complaint. In IMCI the PHCN is encouraged to spend more time with the mother and child, seeking out all symptoms. She is guided by the IMCI chart (booklet). According to WHO (2002:22-26), IMCI strategy implementation uses three strategies when targeting a case, that is, management, community involvement and improving the health system. So $I M C I$ needs a cooperative community.

According to Lambrechts, Byce and Orinda (1999:582-594), in order to improve awareness and health practices in IMCI, parents have to be closely involved in the child's health care. The PHCNS have to explain the condition to the mother who will then be asked to repeat those details back to the PHCN. The first dose of medication is to be given by the parent under the observation of the PHCN. Diagrammatic instructions are given to parents as reminders of when and how to give medication.

All these activities must take place at the clinic during consultation of a patient. According to Chaudhary, et. al (2005:737) culture influenced the careseeking behaviour of the community. This supports this study as the community in this study was still influenced by the way they were treated at the clinic before the introduction of IMCI. They still wanted to leave the clinic with heaps of medication as before. They disapproved health education as the only means of treatment.

Participants indicated that some mothers delayed bringing their children to the clinic until they were very ill.

"These mothers who bring the children when they are very ill when asked, they say that they are bored hecause they bring the child at an early' stage of the illness they will be given health educarion instead of medication. So they delay at home until such a time".

It was found in this study that children suffering from fever, diarrhoea and urinary tract infection were treated at home, they were only brought to the health units when they developed lifethreatening symptoms. This was complicated by their poor attitude to health drugs in health units (Merrick, 2003: 721-730). 
Participants indicated that some mothers doubted their knowledge about treatment of illnesses as they saw them checking the booklets during assessment and treatment of their children. Mothers thought that they were doing so because they did not know what to do. This was supported by the participant who said.

"One mother asked me, why I was checking from the book during and after assessment. Whether it was because her child was suffering from the disease that I didn't know or the child is seriously ill."

According to McGrath, Reid and Boore (2003:555-565), inappropriate reaction from the patients and relatives causes job burnout in the provider. In IMCI, after the PHCN has assessed the child, she/he must check and compare the findings on the assessment form with the appropriate treatment on the treatment chart for proper diagnoses and treatment.

PHCN said that this situation prevented them from building up a continuous relationship with the mothers during implementation of IMCI. This was supported by a participant who said:

"This non-cooperative behaviour by" the mothers makes it difficult for us to build a good nurse-patient relationship."

According to Manojlovich and Ketefian (2002:15-34), nurses value the ability to start and sustain a therapeutic relationship with patients, and have control over them. If mothers are not cooperative this will not be achieved, hence burnout.

\section{$o$ Lack of support from the me-}

\section{dia}

Participants were not satisfied about the way in which clinic incidents were reported on television, radio and in the newspaper. One respondent said:

"When a clinic incident is reported in the media or newspapers by whoever, it is like the nurse has alread! been found guilty."

PHCNS saw it as being a judgmental report as the nurse was reported as being guilty of an offence without even listening to the nurse's side of the story. Such reports influenced the community to undermine the service of the PHCNS implementing IMCI.

Participants said that they once listened to the radio Phalaphala FM station broadcast. There was a live discussion on clinic services conducted by the radio presenter and Tshilidzini hospital management. The community members who participated included one who had received health services from Shayandima catchment area clinic. $A$ participant indicated that.

"Most of questions repeated were on the implementation of IMCI The community showed dissatisfaction about the long assessment period, long queves, being given health education instead of medication. The hospital representatives at the studio repeated the same answers as they were asked the same questions in different ways. " This suggested that the community lacked information about IMCI.

\section{o Lack of political support}

Participants said that politicians usually took first-hand information and reacted or responded there and then to the media. PHCN cited an example of what once happened and said:

"There is a nurse who was suspended from duty by the then Member of $E \mathrm{r}$ ecurive Council of Health (MEC) with immediate effect when the case was reported to him. The very $M E C$ for Health liffed the suspension immediately after hearing the incident from the side of the Democratic Nurses Organisation of South Africa (DENOSA) because he realised later that it was uncalled for. The clinic nurse's work is not appreciated much by almost all people they serve."

Politicians reacted negatively and went straight to the media before having heard the other side of the incident. It was as if they already knew, or as if it was obvious that the nurse was guilty of an offence. This contributed to the PHCNS burnout as the nurses became frustrated with no shoulder to lean on. It also encouraged the community to look down upon nurses and nursing. They come to the clinic with a negative attitude, already knowing that they would always be heard first. Support is a corner stone in climbing the stairs to success hence support of the PHCNS by the stakeholders would improve the implementation of IMCI. PHCNS would be able and willing to render IMCI services fully though in some of the clinics much had to be done since they were not equally affected.

\section{o Signs and symptoms related to work overload}

Workload issues lie behind much of the work-related stress experienced by workers, which in the end has a negative impact on the individual, resulting in burnout which affects one's health. It affects people differently. This is supported by a participant who said:

"Afier working for a long time I usually peep outside to check patients who are still in the queue. When I found that the benches are still full of patien's waiting to consult me, I feel exhausted because it is like I haven't started working at all."

A heavy routine workload leaves little or no time to deal with the emergencies that add to the feeling of being out of control that is so much part of stress. When employees are tired, stressed or unhappy, productivity ultimately suffers. According to Adali and Priami (2002:20), burnout affects the worker with both somatic and psychological symptoms. Stress causes severe health problems and in extreme cases, can cause death. Psychosomatic illness originates from such situations. Participants indicated that some of them were pulling out or looking for other jobs.

Some of the PHCNS had left the clinic for greener pastures and some of those wanted to quit. PHCNS indicated that some of the clinic nurses were leaving because of poor working conditions. These might be the reason why some of them were now thinking of going abroad. This was supported by participants:

"I'm failing to leave because I was not getting a post elsewhere. This time I will grasp any post I come across even if it's of a lower level. One can be happy to leave the place. One can sav Oh, what a relief"

This supports a study by Lehmann and Saunders (2002:133) that some South African nurses go abroad because of poor working conditions. 
Some of the reasons for migration among PHCNS, according to Mariani, Gcaba and Dalton (2003:7), are staff shortages and no recognition. According to WHO (2003-2007:14), retention of health personnel in health service was a problem because there was an increase of workload related to introduction of new health-care strategies. These were similar conditions to those experienced by PHCNS in the clinics. The employer in turn faced the greater challenges of impaired job performance like failure of the PHCNS to implement IMCI. PHCNS worked longer hours than expected as at times they knocked off later than 16H00. This meant that the PHCNS were also exposed to an environment which affected their health and safety, as they knocked off being exhausted and did not have enough time to rest.

PHCNS indicated that they experienced an increase in the number of patients visiting the clinics after the introduction of free health services. In support of this participants said:

"It's always like this in this clinic. There is too much work. During the week it is even worse, it is hectic. We consult even after working hours atmost every day. We consult about 70 to 90 babies being the two of us, excluding other patients. We don't even check the knocking off time as the rule is clear that no patient should be returned home unattended to. So we do work to after $16 H 00$ in most instances."

This implied that the PHCNS had to deal with the large numbers of patients who were coming to the clinic therefore increasing the PHCNS workload. According to the study done by Nemathaga (2005:64), there is an increase in the utilization of clinics and health centres by the community due to the introduction of free health services. PHCNS took calls at night and regardless of working during the night. they were expected to work a full day the following day. In some instances the PHCN would be working with the enrolled nurse, and was expected to consult all the patients. They associated this with lack of sleep and rest. with tiredness, headaches, forgetfulness and loss of concentration.

"I report on duty on Wednesdav and go home the following Wednesday. Meaning that I take 7 nights call. I am expected to work a full day irrespective of whether I have worked during the night or not. Whether I am tired or not, though we are compensated on this but it is not healthy at all."

This study revealed that the PHCNS' working conditions left them without enough sleep. PHCNS indicated that they had very little time to sleep when they were on call, since they could be called at any time to attend to a patient who needed emergency attention.

In almost all the clinics participants indicated that they had to take calls and in spite of working during the night they were expected to work normal hours the following day.

\section{Recommendations}

The following recommendations were made based on research findings, to ensure effective implementation of the IMCI strategy by the PHCNS.

\section{Recommendations regarding dealing with lack of human resources}

According to Karamagi, et. al (2004:39) time required for case management varied from 8-20 minutes. If these findings are applied at Shavandima catchment area where they work 8 hours per day, this means that a PHCN will be able to treat about 7 children per day when using IMCI strategy. The present staff establishment is far less than this expectation. There is therefore a need to increase staff.

- $\quad$ Clinics should be fully staffed, with at least two or three PHCNS who are IMCI trained who will focus solely on rendering $I M C I$ services.

- At least five enrolled nurses and three auxiliary nurses should be allocated per shift per clinic. The staff establishment should be assessed periodically and the necessary changes be made every year.

- According to Khan, Ahmed and Saha (2000:80) the government will use the personnel cost for IMCI implementation if the low cost human resources are employed at the first level health centres. Therefore training of other lower categories of human resources may be introduced at Shayandima catchment area to reduce the demand of work from the PHCNS.

\section{Recommendations regarding dealing with lack of material resources}

According to Chaudhar, et al. (2005:377), implementation of IMCI in the community requires training, sustained supplies of essential drugs and equipment, improved family and community participation with an increase in service utilization.

Sustained supplies of essential drugs and equipment need to be implemented

- $\quad$ The procedure followed for ordering, replacement and repairs should be looked at and be changed so that it is more user friendly.

- Tests kits should be made available immediately upon request so that tests such as HIV and other diagnostic tests are not delayed.

- Telephone lines should be installed at all clinics to ensure effective client-care services.

- An ambulance should be available at all times to deal with emergency services.

- A community member with transport can be given a tender for transporting patients.

- $\quad$ There is a need to sustain clinic supply of essential drugs.

- The system of logistics for supplies should be strengthened and an indicator to monitor the stock of supplies should be put in place.

- $\quad$ The intervals of ordering of medication should be reduced so that they can be able to order as frequently as required.

- $\quad$ Toys should be provided to distract the attention of the child during examination.

- Each clinic should be given a computer to ensure that they will be able to access updated information fast and produce stationery needed for IMCI implementation, e.g. assessment forms. 

technology products should be available and accessible.

- $\quad$ PHCN should be computer trained.

It is shown that under normal operating circumstances, and in the context of a good facility infrastructure and management support, IMCI is associated with improvement in some important aspects of care Chopra, Pates, Choele, Sanders, and Peterson (2005:2). In some clinics the rehydration corner was not even up to the prescribed IMCI standard, as it did not even serve the purpose.

- $\quad$ New buildings should be erected where more rooms are needed for IMCI implementation.

\section{Recommendations regarding provision of supervision and support to PHCN}

According to Chaundry, et. al (2005:737) the supervisors training enabled them carry out a systematic and supportive follow up to observe case management, reinforce skills and solve problems encountered during the rendering of IMCI services.

- $\quad$ This strategy of training supervisors using the 3 davs follow up visits may be good if well implemented.

- $\quad$ Training of supervisors according to the WHO guidelines is important so that they will be able to understand the environment under which PHCN are operating IMCI.

- Supervision needs to be strengthened. This should be strengthened from the politicians above to the nurses on the ground.

- A monitoring tool will make life easier as it will guide the supervisor at each level on why, whom, who, when, what and how to assess.

\section{Community awareness}

- The family and community structures should participate in IMCl implementation.

- The community should be made aware of IMCI.

- Pamphlets written in the lan- guages understood by the community, should be placed where the community could gain access to information related to IMCI.

- $\quad$ Clinics should be provided with information on research findings related to IMCI for update knowledge.

\section{PHCN health assistance}

- Staff fatigue self-assessment tool will help nurses to identify non-job-related factors in their lives that may cause fatigue.

- Work environment fatigue-assessment tool - to pinpoint the problems in the clinic that are contributing to fatigue and implement a rejuvenating solution should be utilized.

- A resource reference section have a list of resources and services within the clinic or community that provide services that can relieve and reduce stress and fatigue.

\section{Recommendations to policy makers}

- $\quad$ Planning for resources should be done before a new programme is started. This means that a special budget should be put aside.

- $\quad$ Continuous monitoring should be done to ensure that problems are identified and addressed immediately.

- Mentoring programmes implementers will assist in providing support to PHCNS.

- $\quad$ Piloting the new programme beforehand could assist in addressing the unplanned circumstances

- Communication strategy with all stakeholders involved is important, including the community who are the recipients of sernice, to avoid taking them by surprise and to encourage them to buy in and support the strategy.

\section{Recommendations regarding further research}

- $\quad$ Research in areas such as the role of cultural factors involved in child care and the impact of health policies on implementation of IMCI.

- Evaluation research should be conducted to see whether IMCI is beneficial to the community or not.

\section{Recommendations regarding nursing education}

- $\quad$ IMCI should be incorporated in all nursing education programmes.

- $\quad$ All nurse educators should be trained as IMCI facilitators.

- $\quad$ Nurse educators and students should be encouraged to implement the IMCI strategv.

\section{Limitations of the study}

The research was conducted in Vhembe District under Shayandima catchment area and this may not necessarily represent the experiences of all $P H C N S$ rendering IMCI services in Limpopo Province. The findings cannot be generalized.

\section{Summary}

The research identified that $I M C I$ is economical when implemented fully; therefore health service support has to be strengthened for the improvement of the health services. Utilization of various research recommendations will help the government improve the health services. This will help to reduce some of the difficulties experienced by the PHCNS in implementing IMCI services.

\section{References}

ADALI, E \& PRIAMI, M 2002: Burnout among nurses in intensive care Units, internal medicine and emergency departments in Greek hospitals. Intensive Care Units and Nursing Journal 10(11)19-38.

BABBIE, E 2004: The practice of social research. $10^{\text {ih }}$ Edition. Thomson Wadsworth: United States of America.

BABBIE, E \& MOUTON, J 2002: The practice of social research. Oxford: University Press.

BRINK, HL 2006: Fundamentals of research methodology for health care professionals. Cape Town: Juta \& com- 
pany.

BRYCE, J; VICTORA, C \& HABICHT, J 2004: The multi-country evaluation of the IMCI strategy: Lessons for the evaluation of public health interventions. American Journal of Public Health. 94 (3). 406-411.

BURNS, N \& GROVE, SK 2001: The practice of nursing research, conduct, critique \& utilization. Philadelphia: WB Saunders company.

CHAUDHARY,N; MOHANTY, PN \& SHARMA, M 2005: IMCI follow up of basic health workers. Indian Journal Paediatrics. 44 (47) 735-739.

CHOPRA, M; PATES,S; CHOELE, K; SANDERS, D \& PETERSON, S 2005: Effect of an IMCI intervention on quality of care across four districts in Cape Town, South Africa. Achieves of disease on childhood. 90. (4) 397-398

CRESWELL, JW 1996: Research design: Qualitative and quantitative approach. Thousand Oaks: Sage Publications.

CRITCHTON, AC \& BOTMAN, Y 2002: Achieving better learning. $A$ computer-mediated instruction. A success story. International Health Profession Education Conference. South Africa.

DE VOS, AS; STRYDOM, H; FOUCHE, CB \& DELPORT, CSL 2002: Research at grass roots. $2^{\text {nd }}$ edition. Pretoria: Van Schaik.

GREENGLASS, ER \& BURKE, RJ 2002: Hospital restructuring and burnout. Journal of Health and Human Services Administration. 25 (1) 89-114.

HENNING, E; VANRENSBURG, W \& SMIT, B 2002: Finding your way in academic writing. Pretoria: Van Schaick Publishers.

HOLLIDAY, A 2002. Doing and writing qualitative research. London: Sage.

IGUMBOR, EU; BRADSHOW, D \& LAUBSCHER, R 2003: Morbidity Profile from registered deaths for the Limpopo Province, South Africa 1997. 2001. South African Medical Research
Council. South Africa. Cape Town: University of Venda.

KAMARAGI CAS; LUBANGA, RGN \& HEGGENHOGEN, P 2004: Health providers counselling of care givers in IMCI program. Pupmed:University of Makerere 431-39(I).

KHAN, MM; AHMED,S \& SAHA, KK 2000: Implementing IMCI in a developing country: Estimating the need for additional health workers in Bangladesh. Human resource for health development iournal (HRDJ) 4 (2) 73-82.

LAMBRECHTS, T; BYCE, J \& ORINDA, V 1999 : IMCI: a summary of experiment. National Library of medicines now. 77 (7) 582-594.

LEHMANN, U \& SAUNDERS, D 2002: Investigating the roles and functions of clinic supervisors in three districts in the Eastern Cape Province. HST Technical Report. Durban: Health System Trust.

MANOJLOVICH,M \& KETEFIAN,S 2002: The effects of organizational culture of nursing professionalism: Implication for health resource planning. The Canadian Journal of Nursing Research. 33. 15-34.

MARIANI, D; GCABA, R \& DALTON, J 2003: Survey on, attitude and practice (KAP) on professional nurses working at the PHC level in Kwazulu-Natal.

http://www.kznhealth.govt.za/italian/ kapsurvey.pdf

MAYAN, MJ 2001: An introduction to qualitative methods: A training module for students and professionals.

MCCOY, D; BESSER, M; VISSER, R \& DOHERTY, T 2002: Interim Findings on the National PMTCT Pilot Sites. Durban: Health Systems Trust.

MCGRATH, A; REID, N\& BOORE, J 2003: Occupational stress in nursing. International Journal of Nursing Studies. 40(5) 555-565.

MERRICK, J 2003: Prevalence of childhood illnesses and care in rural Uganda. The Scientific World Journal 33: $21537-1744$.
NEMATHAGA, L 2005: Experiences of primary health care nurses regarding the provision of free health care services in the Northern region of the Limpopo Province. Unpublished Masters Dissertation. University of Venda.

NEWMAN, WL 2000: Social research methods: qualitative and quantitative approaches. $4^{\text {th }}$ edition. United States of America: Pearson Education company.

POLIT, DF \& BECK, TC 2006: $E s$ sentials of Nursing Research methods, appraisal and utilization. $\sigma^{\text {th }}$ edition. Phyladelphia. Lippincot.

RED CROSS WORKS. 2003: To keep children healthy. Http:// www.redcross. 12 November.

RICE, PI \& EZZY, D 2001: Qualitative research methods. A health focus. New York: Oxford.

TARUS, M 2004: Chief of Department for mother and child assistance. Ministry of Health: Moldova.

TERRE BLANCHE, MT \& DURRHEIM, K 2004: Research in practice moonSTATS CD \& user guide Applied methods for the social science. Cape town: University of Cape Town Press.

UNITED NATIONS CHILDREN'S FUND. 2000: IMCI: An initiative for effective care management. UNICEF: End Decade databases.

WORLDHEALTHORGANISATION. 2002: Regional office for Africa IMCI Newsletter. Editorial IMCI pre-service training. 5(3)

WORLDHEALTHORGANISATION. 2003: Regional office for Europe. IMCI information source 02 November.

WORLDHEALTHORGANISATION. 2003-2007: Country cooperation strategy: Botswana. Regional offices for Africa: Brazaville.

WORLDHEALTHORGANISATION. 2004a: Child and adolescent health and development, Analytic review of IMCI strategy.

WORIDHEALTHORGANISATION. 
2004b: Child and Adolescent health and development, IMCI.

WORLDHEALTHORGANISATION \& UNITED NATIONS CHILDREN'S

FUND. 2002a: South African adaptation $I M C I$.

WORIDHEALTHORGANISATION \& UNITED NATIONS CHILDREN'S FUND. 2002b: IMCI Take-home booklet. South African adaptation.

WIRZBA, H \& JUNCKER, T 1995:

Disease patterns, treatment practices and drug requirements in rural $\mathrm{MCH}$ FP government facilities of Bangladesh. Dhaka: Published report, ICDDR.B. 